\title{
C-type natriuretic peptide prevents angiotensin II-induced cardiac remodelling and dysfunction
}

\author{
Konstanze Roloff ${ }^{{ }^{*}+}$, Franziska Werner ${ }^{1 * \dagger}$, Marco Abeßer $^{1}$, Katharina Völker ${ }^{1}$, Hideo A Baba ${ }^{2}$, Kai Schuh', \\ Michaela Kuhn ${ }^{1}$ \\ From 7th International Conference on cGMP Generators, Effectors and Therapeutic Implications \\ Trier, Germany. 19-21 June 2015
}

\section{Background}

Hypertensive cardiac remodelling is a major risk factor for cardiovascular morbidity and a leading cause of chronic heart failure. The activation of the renin-angiotensin system plays an important pathophysiological role in hypertensive cardiac remodelling [1].

C-type natriuretic peptide (CNP) belongs to the natriuretic peptide family. In the cardiovascular system, CNP is secreted from endothelial cells and possibly from cardiac fibroblasts, to act as autocrine/paracrine hormone [2]. It activates the guanylyl cyclase B (GC-B) receptor which synthesizes the second messenger cGMP. In vitro the CNP/GC-B pathway inhibits the proliferation and collagen synthesis of cardiac fibroblasts [3]. Therefore, we aimed to study the cardiac effects of synthetic CNP on Angiotensin II (Ang II)-induced cardiac fibrosis and hypertrophy in vivo.

\section{Methods and results}

In primary cultured murine cardiomyocytes and cardiac fibroblasts, CNP induced strong and concentrationdependent increases in intracellular cGMP contents. In comparison, the cGMP responses to ANP were much smaller. To analyze CNP effects on Ang II-induced arterial hypertension and cardiac remodelling, 2-months old male C57/Bl6 mice were treated with vehicle (saline), CNP, Ang II or Ang II combined with CNP (12 mice per group). Osmotic minipumps filled with Ang II (delivery of $2000 \mathrm{ng} / \mathrm{Kg} \mathrm{BW/min)} \mathrm{and/or} \mathrm{CNP}$ (50 $\mathrm{ng} / \mathrm{Kg} / \mathrm{min}$ ) or vehicle were implanted subcutaneously during 2 weeks.

\footnotetext{
* Correspondence: konstanze.roloff@uni-wuerzburg.de; franziska.werner@uniwuerzburg.de

† Contributed equally

${ }^{1}$ Institute of Physiology, University of Würzburg, Würzburg, Germany

Full list of author information is available at the end of the article
}

Infusion of Ang II provoked significant increases in diastolic (by $12 \pm 2 \mathrm{mmHg}$ ) and systolic blood pressure levels (by $38 \pm 3 \mathrm{mmHg}$; tail cuff measurements in awake mice). These hypertensive effects were accompanied by significant left ventricular (LV) hypertrophy (with enhanced LV weight/BW and enlarged myocyte diameters), LV interstitial fibrosis (quantified in sirius red stained LV sections) and enhanced mRNA expression of the hypertrophy marker brain natriuretic peptide (BNP, determined by qRT-PCR). Notably, CNP did not alter baseline blood pressure levels or the hypertensive reactions to Ang II. However, the peptide markedly and significantly prevented the cardiac hypertrophic and profibrotic actions of Ang II, as demonstrated at the organ, cellular and molecular (BNP) level.

To evaluate cardiac contractile functions, LV pressurevolume relationships were recorded by LV catheterization in anesthetized mice. LV contractile and relaxation functions of Ang II-treated mice were only mildly altered, as evidenced by subtle changes in LV diastolic pressures, contraction/relaxation rates, ejection fractions and stroke work. LV end-systolic pressures were enhanced, consistent with the enhanced afterload. Remarkably, CNP did not alter baseline LV hemodynamics but significantly improved LV contractility of Ang II-treated mice. Lastly, LV mRNA expression levels of the fibrosis markers collagen I and connective tissue growth factor (CTGF) were analyzed by quantitative real time RT-PCR. Ang II provoked 2.5-fold increases in collagen I and CTGF. Simultaneous infusion of CNP significantly prevented the increases in collagen levels and had no effect on CTGF.

\section{Conclusion}

In our experimental study infusion of a low dose CNP largely prevented the deleterious structural cardiac 
changes which follow neurohormonal activation by Ang II. These anti-remodelling effects of CNP possibly account for the improved cardiac contractile functions. Strikingly, these cardiac protective effects of CNP were fully blood pressure independent. The view that augmentation of cyclic GMP signaling in general benefits heart failure patients is supported by the recent clinical observation that a drug combining blockade of the Ang $\mathrm{II} / \mathrm{AT}_{1}$-receptor with inhibition of neprilysin, a peptidase which degrades ANP and BNP, diminished the risks of hospitalization and death [3]. The here presented and other published experimental observations [4] suggest that the CNP-cGMP pathway may also represent a target for heart-protecting therapies.

\section{Acknowledgment}

This work was supported by the Comprehensive Heart Failure Center (CHFC) in Würzburg (BMBF 01 EO1004) and by Bayer Health Care (Grants4 Targets Initiative).

\section{Authors' details}

${ }^{1}$ Institute of Physiology, University of Würzburg, Würzburg, Germany.

${ }^{2}$ Institute of Pathology, University Hospital of Duisburg-Essen, Germany.

Published: 2 September 2015

\section{References}

1. Yang M, Zheng J, Miao Y, Wang Y, Cui W, Guo J, Qiu S, Han Y, Jia L, Li H, Cheng J, Du J: Serum-Glucocorticoid regulated kinase 1 regulates alternatively activated macrophage polarization contributing to Angiotensin Il-induced inflammation and cardiac fibrosis. Arterioscler Thromb Vasc Biol 2012, 32(7):1675-1686.

2. Horio T, Tokudome T, Maki T, Yoshihara F, Suga S, Nishikimi T, Kojima M, Kawano Y, Kangawa K: Gene expression, secretion, and autocrine action of C-type natriuretic peptide in cultured adult rat cardiac fibroblasts. Endocrinology 2003, 144(6):2279-2284.

3. McMurray JJ, Packer M, Desai AS, Gong J, Lefkowitz MP, Rizkala AR, et al: Angiotensin-neprilysin inhibition versus enalapril in heart failure. $N$ Engl J Med 2014, 371(11):993-1004

4. Wang Y, de Waard MC, Sterner-Kock A, Stepan H, Schultheiss HP, Duncker DJ, Walther T: Cardiomyocyte-restricted over-expression of C-type natriuretic peptide prevents cardiac hypertrophy induced by myocardial infarction in mice. Eur J Heart Fail 2007, 9(6-7):548-557.

doi:10.1186/2050-6511-16-S1-A78

Cite this article as: Roloff et al:: C-type natriuretic peptide prevents angiotensin II-induced cardiac remodelling and dysfunction. BMC Pharmacology and Toxicology 2015 16(Suppl 1):A78.

\section{Submit your next manuscript to BioMed Central} and take full advantage of:

- Convenient online submission

- Thorough peer review

- No space constraints or color figure charges

- Immediate publication on acceptance

- Inclusion in PubMed, CAS, Scopus and Google Scholar

- Research which is freely available for redistribution

Submit your manuscript at www.biomedcentral.com/submit 